\title{
Inadvertent thermal injury following knee arthroscopic surgery in a pediatric patient
}

\author{
Daegyu Kwon ${ }^{1}$, Byung-Gun Kim², Chunwoo Yang ${ }^{2}$, Jonghun Won ${ }^{2}$, and \\ Yoonjung $\mathrm{Kim}^{2}$ \\ Departments of ${ }^{1}$ Orthopaedic Surgery, ${ }^{2}$ Anesthesiology and Pain Medicine, Inha University School of Medicine, \\ Incheon, Korea
}

Inadvertent thermal injury can occur in pediatric patients under general anesthesia during knee arthroscopic surgery. Here, we report the case of a 10-year-old boy who underwent knee arthroscopic surgery under general anesthesia. After the surgery, he complained of pain in the left lower part of his chin and was diagnosed as having a thermal burn. At three-month follow-up, he recovered without any abnormalities except mild hypertrophy of the wound area. Although rare, arthroscopic surgery has the potential to cause thermal injury from the light source. We recommend that the light source should be connected to the arthroscope before switching the power on and disconnected after a considerable time of switching the power off when not in use.

Keywords: Arthroscope; Burn; Pediatrics.

Arthroscopic knee surgery is one of the most common orthopedic procedures. The techniques and complications associated with this surgery are well established [1,2]. A thermal injury caused by the tip of the arthroscope or fiber-optic light cable end is uncommon; however, owing to the high temperature of the transmitted light, the possibility of a thermal burn has been often discussed and several cases have been reported [3-6]. We present a case of thermal injury caused by the light cable end of the arthroscope in a pediatric patient during arthroscopic knee surgery.

Corresponding author: Chunwoo Yang, M.D.

Department of Anesthesiology and Pain Medicine, Inha University School of Medicine, 27, Inhang-ro, Jung-gu, Incheon 22332, Korea

Tel: 82-32-890-3968, Fax: 82-32-881-2476

Email: everycw@daum.net

ORCID: https://orcid.org/0000-0002-9147-3879

Received: June 27, 2017.

Revised: August 7, 2017.

Accepted: August 22, 2017.

Korean J Anesthesiol 2018 April 71(2): 157-160

https://doi.org/10.4097/kjae.2018.71.2.157

\section{Case Report}

A 10-year-old male patient (height, $137 \mathrm{~cm}$; weight, $30 \mathrm{~kg}$; American Society of Anesthesiologists physical status I) was scheduled to undergo surgery for a tibial avulsion fracture of the right knee. His medical history was insignificant. All other laboratory results were within their respective normal ranges.

Surgery was performed under general anesthesia by using propofol as the induction agent, and airway management was performed with a supraglottic airway (i-gel; Intersurgical Ltd., UK), with $2.5 \%$ sevoflurane as the maintenance volatile agent. The surgery was performed with the patient in the supine position, and disposable paper drapes were used to cover the patient after disinfecting the surgical site. Arthroscopy was performed using a Xenon 300-W lamp light source (T2530; ConMed Linvatec, Utica, NY, USA). The light source was set at $80 \%$ intensity. The fracture was successfully reduced and fixed with two cannulated screws. The total time for surgery was 125 minutes, and no intraoperative complications occurred. Before the nurse switched off the power of the fiber-optic light source, one of the surgeons had disconnected the fiber-optic light cable from the arthroscope. The direction of the light cable end was toward the

(c) This is an open-access article distributed under the terms of the Creative Commons Attribution Non-Commercial License (http://creativecommons.org/ licenses/by-nc/4.0/), which permits unrestricted non-commercial use, distribution, and reproduction in any medium, provided the original work is properly cited. 


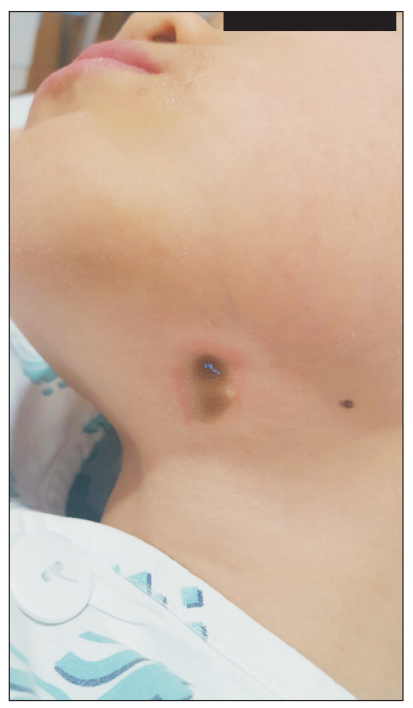

Fig. 1. Full-thickness burns on the left side of the chin; blue-colored parts of the foreign material were observed in the lesion.

head end of the child. Surgeons, anesthesiologist, and nurses did not notice any complication in the patient until the end of surgery. After the patient was moved to the post-anesthesia care unit, he complained of pain in the left lower part of the chin. Two small full-thickness burns measuring 6 and $5 \mathrm{~mm}$ were observed. Redness and edema were observed around the lesions, along with a blue-colored foreign material, which was suspected to be a part of the disposable drape (Fig. 1). The patient's pain continued, and he was immediately referred to a dermatologist. He underwent a follow-up examination of the wound in the department of dermatology for several weeks after the surgery and recovered without any complications, except a mild hypertrophy of the wound area.

\section{Discussion}

Inadvertent thermal injury in the operating room is rare but has been continuously reported. Although it is not associated with mortality, it can result in a permanent disfigurement of the patient [4,5,7-9]. Such injuries can also prolong morbidity and extend hospitalization, appreciably increasing medical costs to the patient and hospital. The hospital and surgical team may also face liability costs if the injured patient sues. A previous closed-claims analysis study reported that the median payment to plaintiff for claims related to burn injury was $\$ 71,375$ (range, $\$ 8,175-321,323)$ [10].

Various medical devices can be implicated in this complication. Several reports in the medical literature described thermal injuries associated with anesthetic care $[11,12]$. Thermal injuries during minimally invasive surgeries have been reported in the settings of abdominal laparoscopic surgery and gastrointestinal endoscopy $[9,13]$. In recent years, cases of thermal injury have been occasionally reported in the setting of orthopedic surgery because of the universal use of minimally invasive arthroscopic surgery. Most of these complications are related to wound irrigation or radiofrequency thermal ablation [5,7-9]. Skin thermal injury from the direct fiber-optic light cable has been reported to be a risk [4].

A previous study showed that burn injury could occur when the skin is exposed for more than 6 hours at $44^{\circ} \mathrm{C}$, or within 1 second at more than $70^{\circ} \mathrm{C}$ [14]. The Xenon light-source cable, widely used in arthroscopic surgery, has the potential to burn surgical drapes, which can result in a direct thermal injury to the patient's skin [3]. According to this study, the measured maximum temperature was more than $100^{\circ} \mathrm{C}$ after 350 seconds at the arthroscopic light cable end, while the arthroscopic tip measured $41.9^{\circ} \mathrm{C}$ after about 200 seconds.

We measured the temperature of the light cable end with a thermocouple, under different situations. The temperature was measured thrice for each situation, and the average of the three readings was considered. We also measured the temperature at different time points and distances from the light-source tip, with varying light intensities (Figs. 2 and 3). The temperature of the tip was more than $200^{\circ} \mathrm{C}$ in the usual setting of arthroscopic surgery (from $80 \%$ to $100 \%$ light intensity) and increased up to $70 \%$ of the highest temperature within 5 seconds. After the power of the light source was switched off, the temperature remained up to $100^{\circ} \mathrm{C}$ for 10 seconds. As the tip of the light source was heated significantly and was at a high temperature even after switching the power off, the surgical team should not switch on the light source without connecting it to the arthroscopic sleeve. As the temperature decreases with increasing distance from the tip of the light source, the surgeon should make a persistent effort to keep a safe distance.

This is a case of thermal injury on the chin caused by an arthroscope light cable tip in a pediatric patient undergoing arthroscopic knee surgery for a knee avulsion fracture. To our knowledge, no previous cases of thermal injury caused by fiber-optic light cable during knee arthroscopy have been reported in a pediatric patient. The inadvertent direct contact of the light cable tip with the skin was the cause of the injury. This injury can best be avoided by following the manufacturer's recommendations. In addition, this case has several characteristics that are different from those of similar cases in adults. First, neuraxial blocks are usually preferred for arthroscopic knee surgery in adult patients, while general anesthesia is preferred for the same surgery in pediatric patients. Therefore, the pediatric patient cannot complain of thermal injury-related pain immediately after onset; hence, the complication is not noticed by the surgeon and/or anesthesiologist. Second, as more parts of the body of the pediatric patient are covered with a surgical drape, the 
A

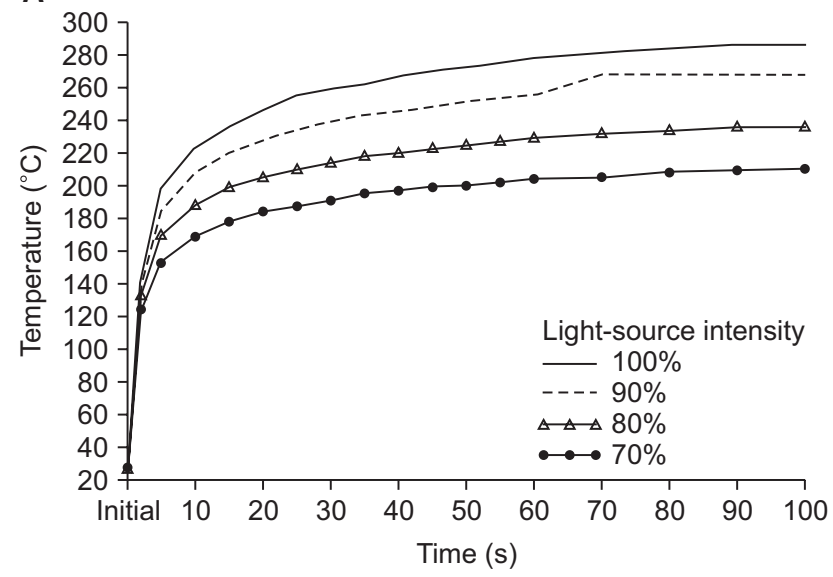

B

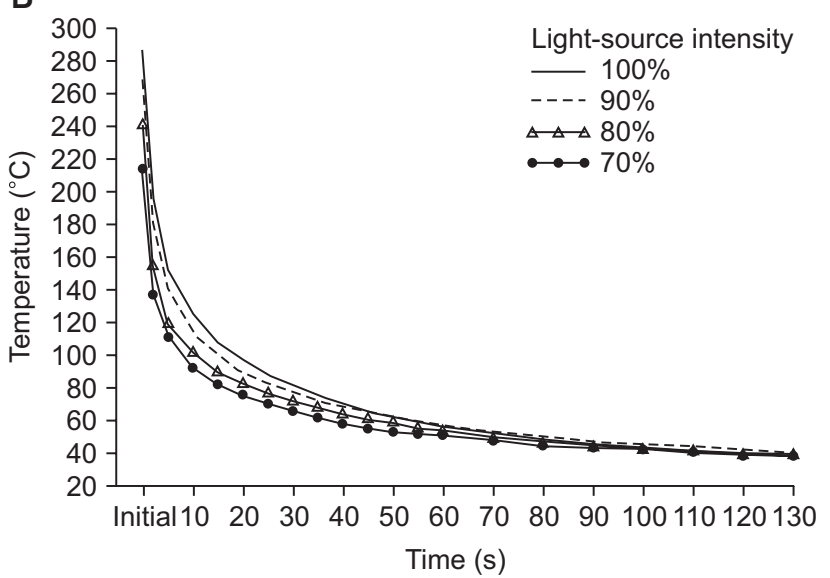

Fig. 2. Change of temperature in the light-source cable with different intensities of light after power on (A) and power off (B).

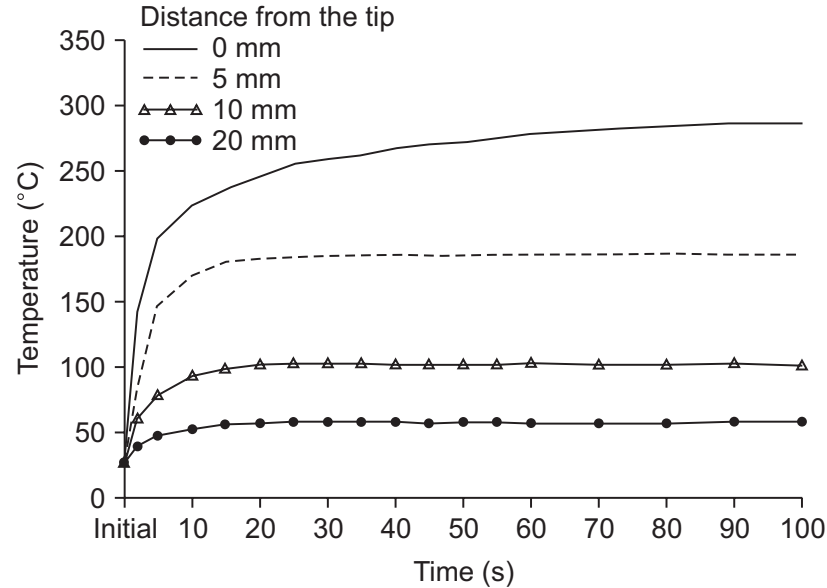

Fig. 3. Change in temperature in the light-source cable by altering the distance from the tip of the light source.

surgeon's view of the patient's face is limited, as compared with that in an adult. We measured the temperature on the side of the light cable and found that it was $38.4^{\circ} \mathrm{C}$, which indicates a low possibility of burn if the tip was not in direct contact with the patient. While the instrument lies around the abdominal area in an adult, it is usually located around the chest in a child because of the relatively short stature. The side of the light source is in contact with the skin in an adult, and burn does not occur even if the light source cable is connected to the arthroscope. Moreover, the abdomen and chest are flat, whereas the chin protrudes in the supine position, and thus, the tip of the light-source cable could be in direct contact with the chin in a child if the instrument is positioned at the upper part of the body.

In conclusion, we present this case to highlight the need for extra vigilance by the surgical team to avoid this potential but early-detectable complication during arthroscopic knee surgery in pediatric patients. We recommend that the light source should be connected to the arthroscope prior to switching the power on and should always be disconnected after a considerable time of switching the power off when not in use.

\section{Acknowledgments}

This study was supported by an Inha University Research Grant.

\section{References}

1. Complications in arthroscopy: the knee and other joints. Committee on Complications of the Arthroscopy Association of North America. Arthroscopy 1986; 2: 253-8.

2. Salzler MJ, Lin A, Miller CD, Herold S, Irrgang JJ, Harner CD. Complications after arthroscopic knee surgery. Am J Sports Med 2014; 42: 292-6.

3. Sandhu H, Turner R, Pozo JL. No smoke without fire--simple recommendations to avoid arthroscopic burns. Knee 2002; 9: 341-6.

4. Lau YJ, Dao Q. Cutaneous burns from a fiberoptic cable tip during arthroscopy of the knee. Knee 2008; 15: 333-5.

5. Pell RF 4th, Uhl RL. Complications of thermal ablation in wrist arthroscopy. Arthroscopy 2004; 20 Suppl 2: 84-6.

6. Smith LP, Roy S. Fire/burn risk with electrosurgical devices and endoscopy fiberoptic cables. Am J Otolaryngol 2008; 29: 171-6.

7. Sheskier SC, Fu FH. Arthroscopic irrigation burn. A case report. Am J Sports Med 1991; 19: 191-3. 
8. Mohammed KD, Hayes MG, Saies AD. Unusual complications of shoulder arthroscopy. J Shoulder Elbow Surg 2000; 9: 350-3.

9. Segami N, Yamada T, Nishimura M. Thermal injury during temporomandibular joint arthroscopy: a case report. J Oral Maxillofac Surg 2004; 62: 508-10.

10. Bhananker SM, Posner KL, Cheney FW, Caplan RA, Lee LA, Domino KB. Injury and liability associated with monitored anesthesia care: a closed claims analysis. Anesthesiology 2006; 104: 228-34.

11. Chung K, Lee S, Oh SC, Choi J, Cho HS. Thermal burn injury associated with a forced-air warming device. Korean J Anesthesiol 2012; 62: 391-2.

12. Lee JY, Park CB, Cho EJ, Kim CJ, Chea JS, Lee BH, et al. Airway fire injury during rigid bronchoscopy in a patient with a silicon stent -a case report-. Korean J Anesthesiol 2012; 62: 184-7.

13. Phillips J, Keith D, Hulka J, Hulka B, Keith L. Gynecologic laparoscopy in 1975. J Reprod Med 1976; 16: 105-17.

14. Moritz AR, Henriques FC. Studies of thermal injury: II. The relative importance of time and surface temperature in the causation of cutaneous burns. Am J Pathol 1947; 23: 695-720. 